This report was prepared as an account of work sponsored by an agency of the United States BNL- -45307 Government. Neither the United States Government nor any agency thereof, nor any of their employees, makes any warranty, express or implied, or assumes any legal liability or responsibility for the accuracy, completeness, or usefulness of any information, apparatus, product, or process disclosed, or represents that its use would not infringe privately owned rights. Reference herein to any specific commercial product, process, or service by trade name, trademark. manufacturer, or otherwise does not necessarily constitute or imply its endorsement, recommendation, or favoring by the United States Governmerit or any agency thereof. The views and opinions of authors expressed herein do not necessarily state or reflect those of the United States Government or any agency thereof.

\title{
Cooperation in Nuclear Data Evaluation Among the OECD Countries
}

\author{
C.L. Dunford
}

Brookhaven National Laboratory, Upton, NY 11973, USA

\section{Y. Kikuchi}

Japan Atomic Energy Research Institute, Tokai-Mura, Japan

\section{Salvatores}

\section{C.E.N. Caderache, Saint-Paul-Lez-Durance, France}

\begin{abstract}
In the fall of 1988 , agreement was reached on a collaborative effort between the four nuclear data evaluation projects which exist within the OECD countries. Those projects participating in this effort are the ENDF/R project in the United States, the JENDL project in Japan and the JEF and EFF projects in Western Europe. The cooperation among these projects has been proceeding under the sponsorship of the NEA Committee on Reactor Physics and the NEA Nuclear Data Committee since 1989. The goals and accomplishments of the Working Group on Evaluation Cooperation and the work of its seven ongoing projects are briefly described.
\end{abstract}

(evaluated nuclear data, ENDF/B, JENDL, JEF, EFF, nuclear reactions)

This work has been supported in part by the U.S. Department of Energy under Contract No. DE-AC02-76CH00016. 


\section{Introduction}

The production of evaluated nuclear data libraries covering materials of interest for applied research is a very expensive activity. In the 1960's there were many different evaluation projects and data libraries within the OECD countries including several in the United States. An AEC-ENEA sponsored seminar, held at Brookhaven National Laboratory in May 1965 reviewed the status of nuclear data evaluation. The participants recommended that European-American cooperation in the field be established[1].

The increasing scope of materials, data types and energy range needed to satisfy demands of a growing user community resulted in the merger of some projects and termination of others. In the United States, nearly all US government sponsored nuclear data activity was merged to form the Cross Section Evaluation Working Group. This resulted in the development of the ENDF system and the ENDF/B data file, a product only of United States and Canadian efforts. Because of the comprehensiveness of ENDF, its associated processing programs and its free availability, the ENDF/B data file became the major source of evaluated nuclear data used in the OECD countries (except for Japan) in the 1970's. The JENDL project was started in the early 1970's in Japan to provide evaluated data for Japanese reactor development programs. A comprehensive summary of the international evaluation activity at that time was made by the IAEA Panel on Nuclear Data Evaluation held in Vienna, 
Austria in 1971[2]. During this period, evaluated nuclear data files were generally available without restriction.

The US decision to restrict distribution of ENDF/B$\mathrm{V}$ spurred formation of other evaluation projects within the European countries, namely JEF and EFF in the 1980's, while Japan continued with the JENDL project. As the end of the decade approached, each project had matured and completed release of an evaluated data file which was considered adequate for use by their user community. Along with this maturity and success came serious funding reductions along with the realization that concentrated and specialized efforts would be required to make future extensions and improvements.

As a result of NEANDC interest in the matter, the NEANDC chairman, Alan B. Smith, Argonne National Laboratory, wrote a letter in January 1988 to chairmen of the JENDL, ENDF and JEF projects stressing the importance which the NEANDC placed on future cooperation between the different evaluation projects and soliciting their suggestions. The positive responses from the projects led to a small exploratory meeting during the Mito Conference to exchange views.

At the NEANDC meeting in Los Alamos, USA, in September 1988, a NEACRP/NEANDC Task Force on Evaluation Cooperation was formed under the chairmanship of John Rowlands, Winfrith, UK. The subcommittee included the chairmen of the the three projects and NEANDC members. During the meeting, agreement in principle was reached on the following items, 1) evaluated 
nuclear data files and associated documentation would be freely exchanged between the different projects, 2) the different evaluated nuclear data files would remain separate entities for the forseeable future, but through increased cooperation, the contents of the different files would tend to merge, 3 ) cooperative evaluation activities should be promoted in order to prevent unnecessary duplication, 4) personnel exchanges would be encouraged, and 5) exchange of benchmark testing results would be considered. .

Following formal agreement from the participating projects: the Task Force met in Paris, France, in May 1989 to arafted the working arrangements of the cooperation which established a NEACRP/NEANDC Working Group on Evaluation Cooperation. The Working Group would consist of up to four members from each of the projects and two representatives from the parent NEA committees. The NEA would serve as secretariat to the Working Group. Technical activities of the Working Group are carried out by Subgroups formed to solve specific evaluation tasks. Six high priority tasks were identified as the first cooperative evaluation activities to be supported by the Working Group. The Task Force held its final meeting at Brookhaven National Laboratory in October 1989 to prepare its final report.

Following acceptance of this report by the NEACRP and the NEANDC, the Task Force was dissolved and the Working Group established. The Working Group met briefly at Argonne National Laboratory following 
the NEACRP meeting to organize and establish the Subgroups. One member of the Working Group was assigned to the monitor work of each subgroup. The Working Group held its first full meeting at Marseille, France, in April 1990 and will hold its next meeting in Petten, the Netherlands, following this conference.

\section{Active Subgroups}

SG1

Intercomparison of files for ${ }^{52} \mathrm{Cr},{ }^{56} \mathrm{Fe}$ and ${ }^{58} \mathrm{Ni}$

- C.Y. Fu, ORNL, Oak Ridge, coordinator

The subgroup was organized to intercompare the evaluations for these three nuclides available from the cooperating projects. The nuclides are major components of stainless steel and have recently been evaluated by all the projects. Graphical intercomparisons have been nearly completed. An effort to understand reasons for the observed discrepancies is in progress. Many suggested improvements to the existing evaluations have been made. The status of this task is described in a paper[3] at this conference.

\section{SG2}

Generation of Covariance Files for ${ }^{56} \mathrm{Fe}$ and ${ }^{n a t} \mathrm{Fe}$

- H. Vonach, IRK, Vienna, coordinator

Covariance data are required to assess uncertainties in design parameters and to refine use of nuclear data in reactor applications. Technology for generating evaluated covariance data is still primitive compared to that 
employed in evaluating cross sections and other nuclear data. This subgroup has been assigned the task of reviewing the existing technology, particularly with respect to these two important reactor materials and recommend methods for providing improved evaluations.

\section{SG3}

Actinide Data in the Thermal Energy Range

- H. Tellier, CEN, Saclay, coordinator

This subgroup was formed to investigate apparent discrepancies between evaluated thermal nuclear constants and those values implied by thermal reactor benchmark studies. It is believed that the discrepancies are related to the temperature coefficient calculation problem. The nuclear data for the major heavy nuclides were reviewed. The only remaining problem concerns ${ }^{23.5} \mathrm{U} \eta$. The Geel and Grenoble measurements do not agree with the ones from Harwell and Oak Ridge. The origin of this discrepancy, which could be due to analysis of the raw data, is under investigation.

\section{SG4}

${ }^{2: 38}$ U Capture and Inelastic Scattering Cross Sections

- Y. Kända, Kyushu U., Fukuoka, coordinator

These cross sections are of primary importance for fast reactors. Recently evaluated data for the capture cross section are significantly lower than the average of measured data in the unresolved resonance region. The normalization of measured data in the resolved resonance region has been studied and it was concluded that older measured values should be renormalized downward. The 
improved agreement seems to resolve this discrepancy. Inelastic data evaluations in JENDL-3 and ENDF/B-VI agree fairly well but are higher than the measured data. New measurements from ANL are expected. The status of this task is described in a paper[4] this conference.

\section{SG5}

${ }^{239} \mathrm{Pu} 1-100 \mathrm{keV}$ Fission Cross Section

- E. Fort, CEN, Caderache, coordinator

The ${ }^{239} \mathrm{Pu}$ fission cross section is important for calculating performance of fast reactors. The high accuracy values obtained from simultaneous evaluation of the standards cross sections for ENDF/B-VI give significantly higher values at the top of the resolved resonance region than does the resonance region evaluation by Derrien and the latest experimental data of Weston.

Experimental programs are being prepared at CBNM and ORNL to check the normalization procedure in Weston's experiments. A re-evaluation of the cross section in now underway at both Los Alamos and Cadarache, taking into account new microscopic and integral information. The work of this subgroup is described in a paper[5] at this conference.

\section{SG6}

Delayed Neutron Data Benchmarking

- A. Filip, CEN Caderache,

- G. Rudstam, Studsvik Energiteknik, coordinators

The discrepancy of up to $10 \%$ in the calculation-toexperiment ratio for integral measurements of $\beta_{\text {eff }}$ result 
in undesirable conservatism in design and operation of reactor control systems. This subgroup is investigating both experimental and theoretical avenues to reduce the uncertainty.

A careful review of present evaluated data uncertainties indicates that they are probably underestimated. It has been suggested that $\nu_{d}$ for ${ }^{238} \mathrm{U}$ may be underestimated. A series of benchmark integral experiments will be performed with the MASURCA reactor in 1992-1993. The accuracy and analysis method for these integral experiments should produce significant new information on $\nu_{d}$ of ${ }^{235} \mathrm{U},{ }^{238} \mathrm{U}$ and ${ }^{239} \mathrm{Pu}$.

\section{SG7}

\section{Multigroup Cross Section Processing}

- R. Roussin, ORNL, Oak Ridge, coordinator

This is a new subgroup formed to coordinate production of a comprehensive library from the ENDF/B-VI, JENDL-3 and JEF-2 libraries using VITAMIN-J specifications . Mainly, the NJOY processing system will be used. Output will be available in the MATXS and AMPX formats. The status of this task is described in a paper[6] at this conference.

\section{Results of Cooperation to Date}

The cooperating projects have agreed that reports, conclusions and any evaluated data resulting from the cooperation will be available world-wide without restriction. Those wishing to obtain specific information should 
contact the secretariat at the Nuclear Energy Agency Data Bank.

The evaluated data files, ENDF/B-VI, JENDL-3 and JEF-1, have been released for distribution world-wide. Those wishing to receive information from one of the files should contact the neutron data center responsible for servicing your country. It is expected that the JEF-2 file will be released for unrestricted distribution after integral benchmark testing is completed.

Seven cooperative projects have been initiated under the sponsorship of this Working Group. Significant progress has already been made in several of these tasks. While there have been important contributions to the ENDF/B-VI, JEF-2 and JENDL-3 libraries from informal cooperative activities, formation of this Working Group has provided a mechanism for exchange of information and for expansion in a more formal way of the sharing of evaluation tasks within available resources.

\section{The Future}

This cooperative effort involves only the evaluation activities of OECD countries. However experts from nonOECD countries are permitted to participate in the work of the subgroups when their special expertise is needed. We shall be exploring the possibility of extending this cooperative effort to projects outside the OECD in the near future.

While we expect existing data files to continue as separate entities for the forseeable future, contents of the 
files should converge with time. The work of the subgroups will tend to resolve differences in approach and conflicts in conclusions of the different evaluators by involving them together in the search for a solution to common problems. The revised evaluated data coming from these joint studies will be reflected in future releases of the data files. In deciding on future tasks for investigation, the Working Group will attempt to assess the priority requirements for nuclear data and to anticipate data needs for innovative reactor concepts.

\section{References}

1. I.Zartman, R.P.Perret, Conclusions of AECENEA Seminar on the Evaluation of Neutron Cross-Section Data, Brookhaven National Laboratory, May 1965

2. Neutron Nuclear Data Evaluation, STI/DOC/10/146, IAEA, Vienna, 1973

3. C.Y.Fu et.al., "Intercomparision of Evaluated Files for ${ }^{52} \mathrm{Cr},{ }^{56} \mathrm{Fe}$, and ${ }^{58} \mathrm{Ni"}$, these proceedings

4. Y.Kanda et.al., "A Report on Evaluated ${ }^{238} \mathrm{U}(\mathrm{n}, \gamma)$ Cross Section", these proceedings

5. E.Fort et.al., "Progress Report on the Subgroup on Pu-239 Fission Cross Section between $1 \mathrm{keV}$ and $100 \mathrm{keV}$ ", these proceedings

6. R.Roussin et.al., "NEACRP/NEANDC Working Group on Evaluation Cooperation: Progress of the Subgroup on Multigroup Cross Section Processing", these proceedings 